\title{
A DFT Treatment of Some Aluminized 1,3,3-Trinitroazetidine (TNAZ) Systems - A Deeper Look
}

\section{Lemi Türker}

Department of Chemistry, Middle East Technical University, Üniversiteler, Eskişehir Yolu No: 1, 06800 Çankaya/Ankara, Turkey; e-mail: lturker@gmail.com; lturker@metu.edu.tr

\begin{abstract}
1,3,3-Trinitroazetedine (TNAZ) is a powerful but insensitive energetic compound having $\mathrm{C}-\mathrm{NO}_{2}$ and $\mathrm{N}-\mathrm{NO}_{2}$ groups attached to a four-membered backbone. Aluminum powders are often added to explosives in order to have enhanced blast effect, etc. In the present study, aluminized TNAZ system is modeled for 1-3 $\mathrm{Al}$ atom(s) per TNAZ molecule within the restriction of density functional theory at the levels of UB3LYP/6$311++G(d, p)$ and UB3LYP/cc-PVDZ. Certain structural, physical and quantum chemical properties are obtained and discussed. The considered properties are found to be highly dependent on the multiplicity (thus the number of $\mathrm{Al}$ atoms present) of the composite systems considered. Also, calculated IR and UV-VIS spectra of the composites have been presented.
\end{abstract}

\section{Introduction}

More powerful but insensitive explosives are continuously searched theoretically and experimentally. An energetic small-ring compound 1,3,3-trinitroazetidine, also known as TNAZ, is the most widely studied explosive recently [1-2]. It is a highly nitrated fourmembered nitrogen heterocyclic ring having $\mathrm{C}-\mathrm{NO}_{2}$ and $\mathrm{N}-\mathrm{NO}_{2}$ groups. It possesses improved performance in comparison to conventional melt castable explosive trinitrotoluene (TNT). The additional contribution of energy is attributed to the presence of strained ring system [3-8]. There are various methods reported for the synthesis of 1,3,3-trinitroazetidine [9].

Received: December 10, 2019; Accepted: January 24, 2020

Keywords and phrases: TNAZ, 1,3,3-trinitroazetidine, aluminum, explosive, density functional theory.

Copyright (C) 2020 Lemi Türker. This is an open access article distributed under the Creative Commons Attribution License, which permits unrestricted use, distribution, and reproduction in any medium, provided the original work is properly cited. 
TNAZ, being a high performance, melt castable explosive, has been proposed as potential replacement for TNT [10]. The low melting point of TNAZ $\left(101^{\circ} \mathrm{C}\right)$ enables the processing of formulations on modified production lines. Its performance is approximately $30 \%$ greater than TNT. It shows excellent thermal stability $\left(>180^{\circ} \mathrm{C}\right)[11]$. TNAZ has many added advantages over known explosives. It is a highly energetic material, more powerful than RDX and is less vulnerable than most other nitramines [12, 13]. Unlike HMX, TNAZ is soluble in molten TNT, and is compatible with aluminum, steel, brass and glass [14-16].

The compatibility of 1,3,3-trinitroazetidine (TNAZ) with some energetic components and inert materials of solid propellants was studied by using the pressure DSC method [17]. On the other hand, desensitization of TNAZ via molecular structure modification has been investigated theoretically [18].

Reactive molecular dynamics simulations of the thermal decomposition mechanism of 1,3,3-trinitroazetidine has been studied where the thermal decomposition of TNAZ crystals at high temperature was calculated by molecular dynamics simulation with the ReaxFF/lg reactive force field. The change in the potential energy of TNAZ, the formation of small-molecule products and clusters, and the initial reaction path of TNAZ were analyzed. The kinetic parameters of different reaction stages in TNAZ thermal decomposition were obtained [19].

On the other hand, aluminized explosives have been used in various formulations since the beginning of the last century. Aluminum powders are added to explosives in order to enhance their blast and heat effects, as well as to increase the bubble energies in underwater explosions [20-24].

\section{Method of Calculations}

The initial geometry optimizations of all the structures leading to energy minima were achieved by using MM2 method followed by semi-empirical PM3 self-consistent fields molecular orbital (SCF MO) method [25, 26] at the restricted level [27, 28]. Subsequent optimizations were achieved at Hartree-Fock level using various basis sets. Then, geometry optimizations were managed within the framework of density functional theory (DFT, UB3LYP) $[29,30]$ finally at the levels of unrestricted $6-311++G(d, p)$ and CC-PVDZ [27, 31]. The exchange term of B3LYP consists of hybrid Hartree-Fock and local spin density (LSD) exchange functions with Becke's gradient correlation to LSD 
exchange [30, 32]. The correlation term of B3LYP consists of the Vosko, Wilk, Nusair (VWN3) local correlation functional [33] and Lee, Yang, Parr (LYP) correlation correction functional [34]. The vibrational analyses were also done. The total electronic energies are corrected for the zero point vibrational energy (ZPE). The normal mode analysis for each structure yielded no imaginary frequencies for the $3 N-6$ vibrational degrees of freedom, where $N$ is the number of atoms in the system. This indicates that the structure of each molecule corresponds to at least a local minimum on the potential energy surface. All these calculations were done by using the Spartan 06 package program [35].

\section{Results and Discussions}

Aluminized energetic materials are not simple admixture of the components. The aluminum atom has $1 s^{2} 2 s^{2} 2 p^{6} 3 s^{2} 3 p^{1}$ ground state electronic configuration. The presence of an unpaired electron in aluminum engenders various multiplicities as the number of it increases.

Table 1 shows some properties of the aluminized TNAZ systems presently studied in which $\mathrm{Al}$ content varies between ca., $12-30 \%$ by weight. Depending on the number of $\mathrm{Al}$ atoms (n:1-3) various spin states are possible. They are indicated in Table 1. The dipole moments of TNAZ is 0.5 debye (UB3LYP/6-311++G(d,P)). So the presence of $\mathrm{Al}$ atoms and thus the multiplicities highly affect the dipole moment values of the composite systems of concern.

Table 1. Some properties of the composites.

\begin{tabular}{lcccc}
\hline Structure & Aluminum percent & MW & $\begin{array}{c}\text { Dipole moment } \\
\text { (Debye) }\end{array}$ & Ovality \\
\hline TNAZ+ Al Doublet & 12.32899 & 219.069 & 4.55 & 1.31 \\
TNAZ+ 2Al Singlet & 21.94301 & 246.051 & 6.19 & 1.36 \\
TNAZ+ 2Al Triplet & 21.94301 & 246.051 & 2.26 & 1.35 \\
TNAZ+ 3Al Doublet & 29.65685 & 273.033 & 2.22 & 1.56 \\
TNAZ+ 3Al Quartet & 29.65685 & 273.033 & 4.67 & 1.39 \\
\hline
\end{tabular}

Dipole moments and ovalities from geometries at UB3LYP/6-311++G(d,P) level. 
Figure 1 shows the optimized structures as well as the directions of the dipole moment vectors of the systems of concern at the level of UB3LYP/6-311++G(d,p). In general, the vectors originate from the site of geminal nitro groups to the single nitro group, being TNAZ+2Al singlet as an exception (see Figure 1).

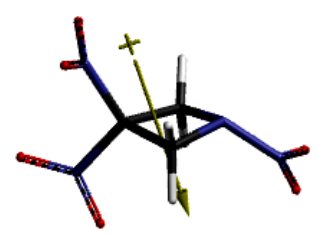

TNAZ

Singlet
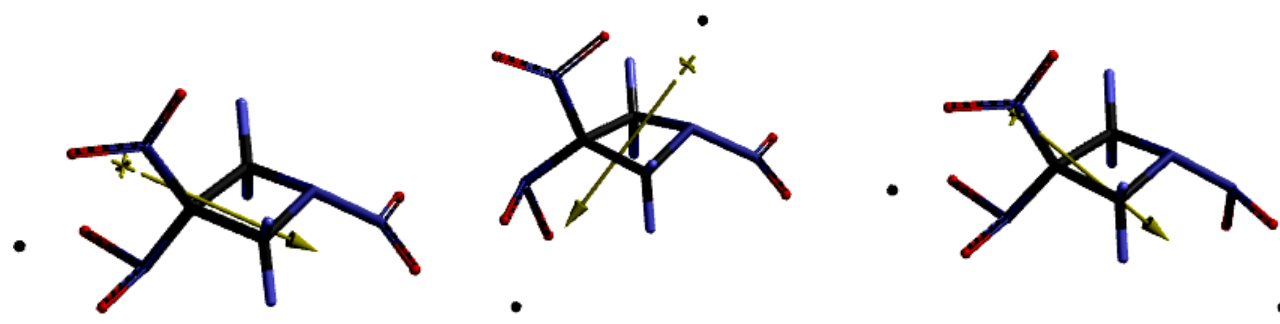

$\mathrm{TNAZ}+\mathrm{Al}$

Doublet

TNAZ $+2 \mathrm{Al}$

Singlet

TNAZ+2Al

Triplet
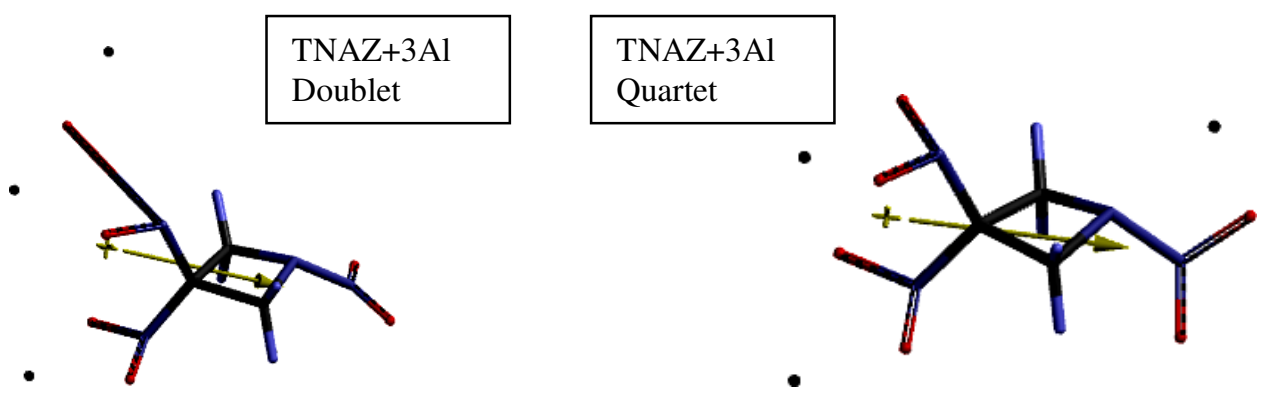

Figure 1. Optimized structures of the composites (UB3LYP/6-311++G(d,p).

Figure 2 displays the optimized structures as well as the directions of the dipole moment vectors of the systems, but this time at the level of UB3LYP/cc-PVDZ. At this level of optimization, there exist some differences in geometries as compared to the previous level of optimization. Also the directions of the dipole moments for TNAZ+2Al cases (the singlet and triplet) are different from UB3LYP/6-311++G(d,p) level of results. The localizations of $\mathrm{Al}$ atoms around TNAZ molecule in TNAZ+3Al doublet case at the both levels of calculations are different. 


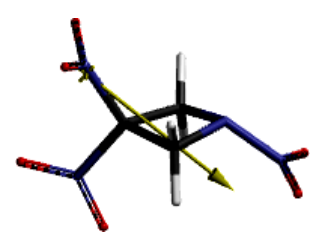

TNAZ

Singlet

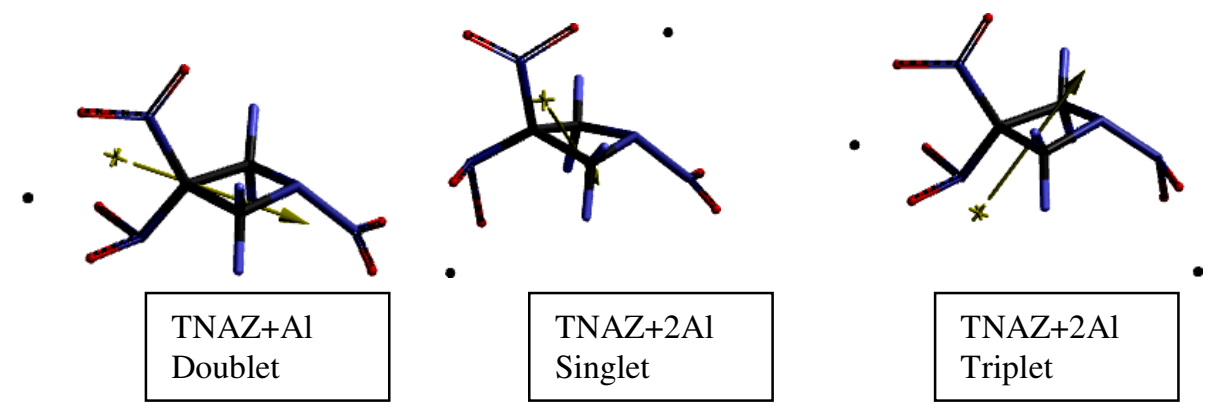

-

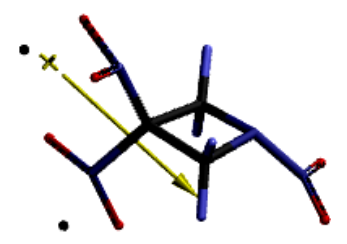

TNAZ+3Al

Doublet

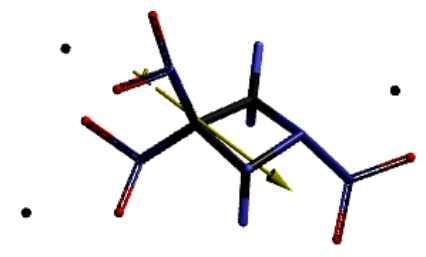

TNAZ+3Al Quartet

Figure 2. Optimized structures of the composites (UB3LYP/cc-PVDZ).

Figure 3 stands for the bond lengths of TNAZ (singlet) at two different levels of calculations which are very comparable. Figures 4 and 5 show the bond lengths of the composite systems of concern at two different levels of calculations employed presently. In general, all the bond lengths are highly dependent on the multiplicities of the systems. Even in the same system $\mathrm{C}-\mathrm{NO}_{2}$ and $\mathrm{N}-\mathrm{O}$ bonds exhibit noticeable differences (e.g., TNAZ+3Al doublet). The N-O bond of this system at UB3LYP/6-311++G(d,p) level is particularly long (4.08 $\AA$ ). However, the same bond length is reasonable at UB3LYP/ccPVDZ level of calculation. Note that normally N-O bond in $\mathrm{NO}_{2}$ group is about $1.24 \AA$ $\left(\mathrm{CH}_{3} \mathrm{NO}_{2}\right), 1.22 \AA$ 兄 $\left(\mathrm{CF}_{3} \mathrm{NO}_{2}\right)[36]$. 


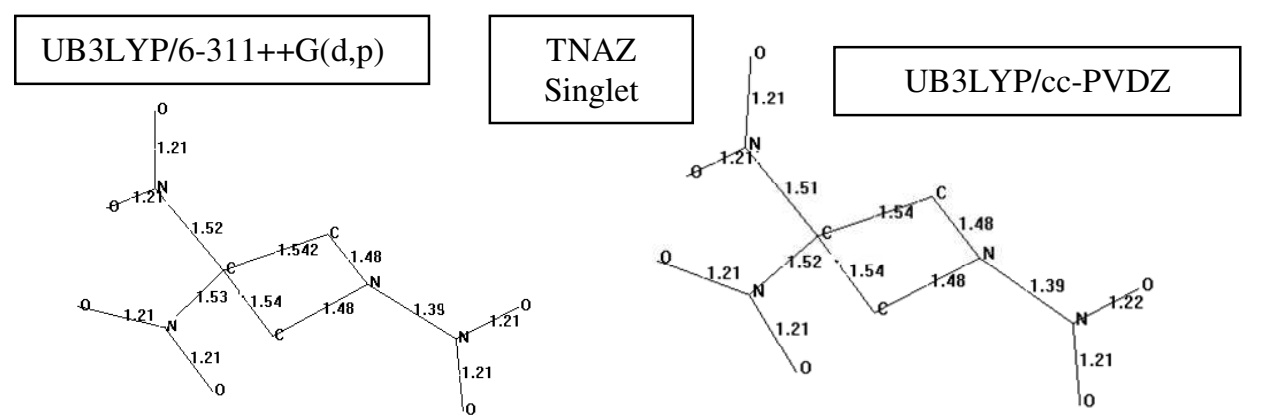

Figure 3. Bond lengths $(\AA)$ of TNAZ (Hydrogens not shown).
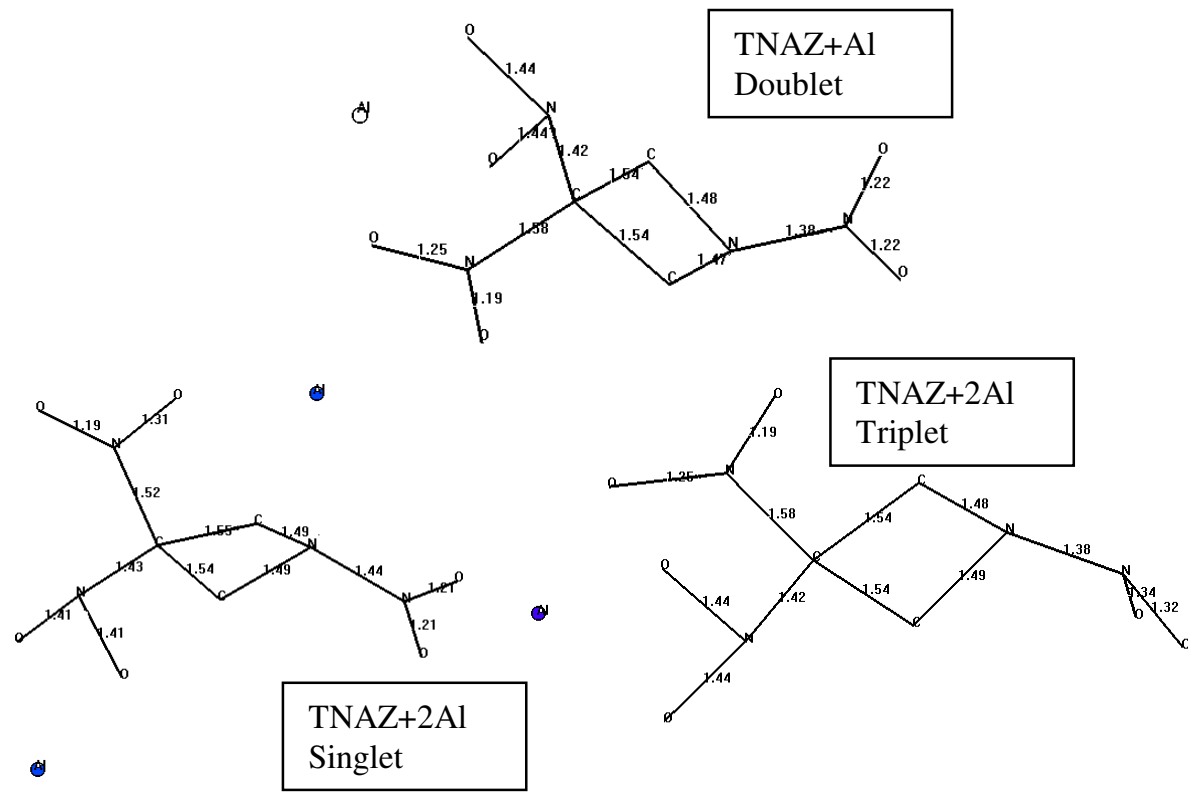

$(9$
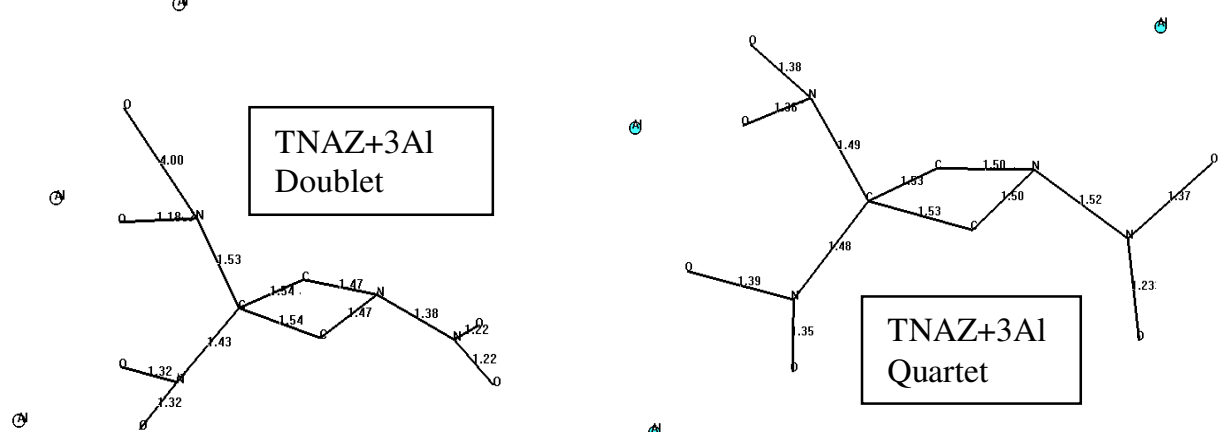

상

Figure 4. Bond lengths $(\AA)$ of the composites (Hydrogens not shown, (UB3LYP/6$311++\mathrm{G}(\mathrm{d}, \mathrm{p}))$. 

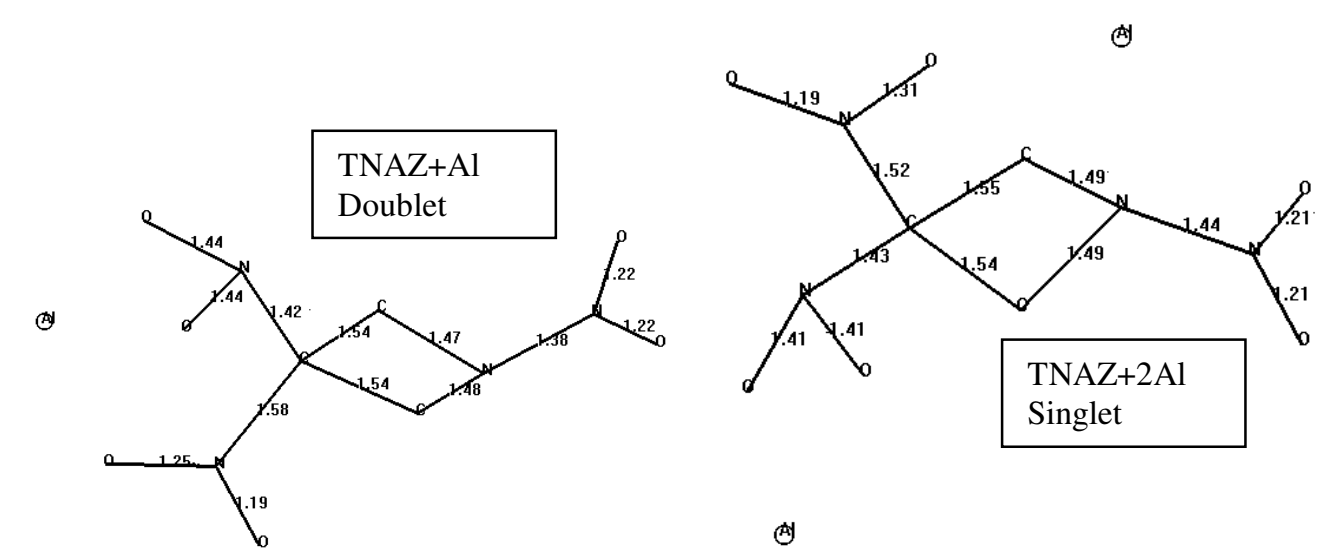

4

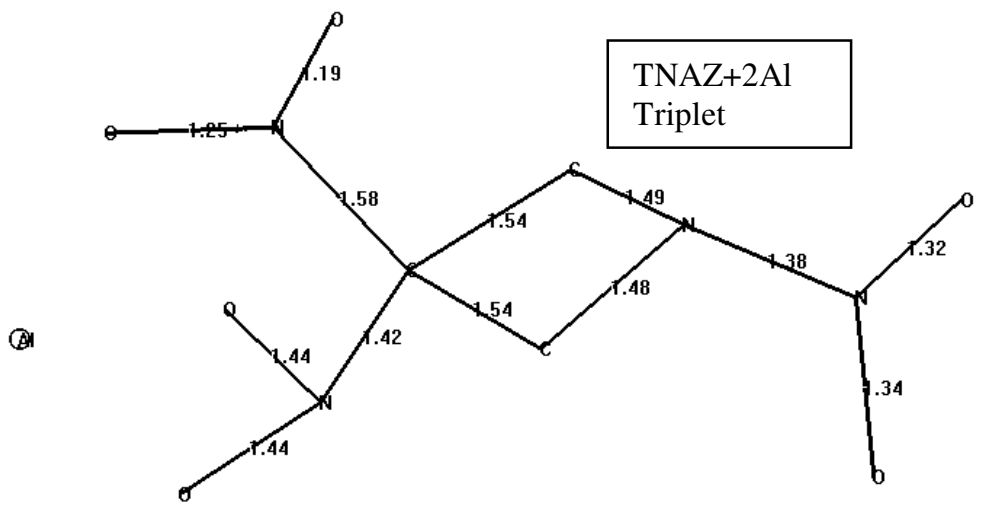

Q11

$0^{\prime \prime}$
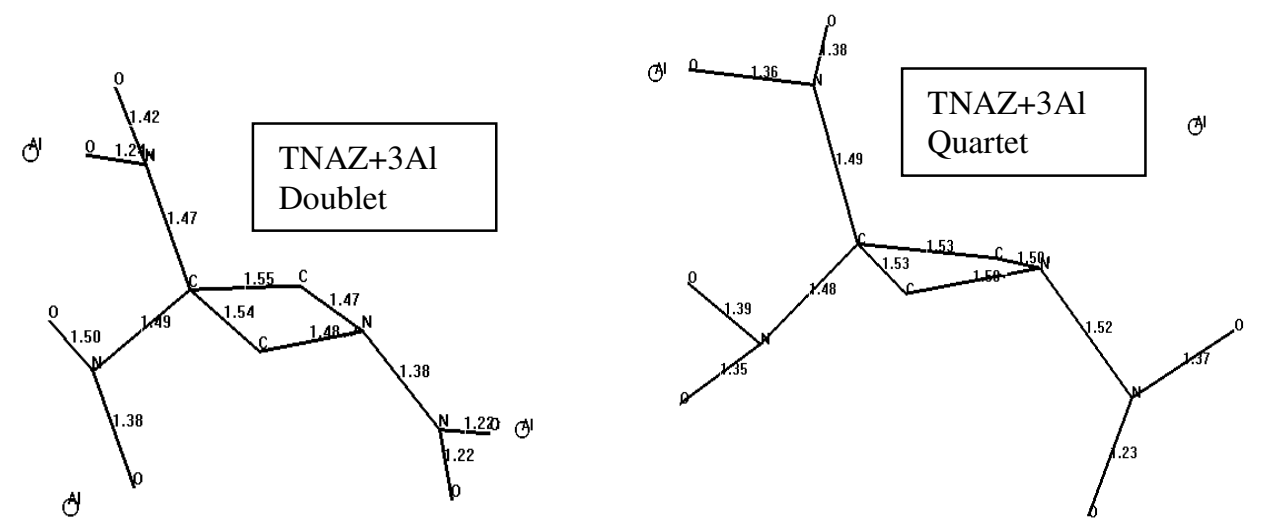

Figure 5. Bond lengths $(\AA)$ of the composites (Hydrogens not shown, (UB3LYP/ccPVDZ)). 
Figure 6 shows the IR spectra of the composite systems of present concern at the
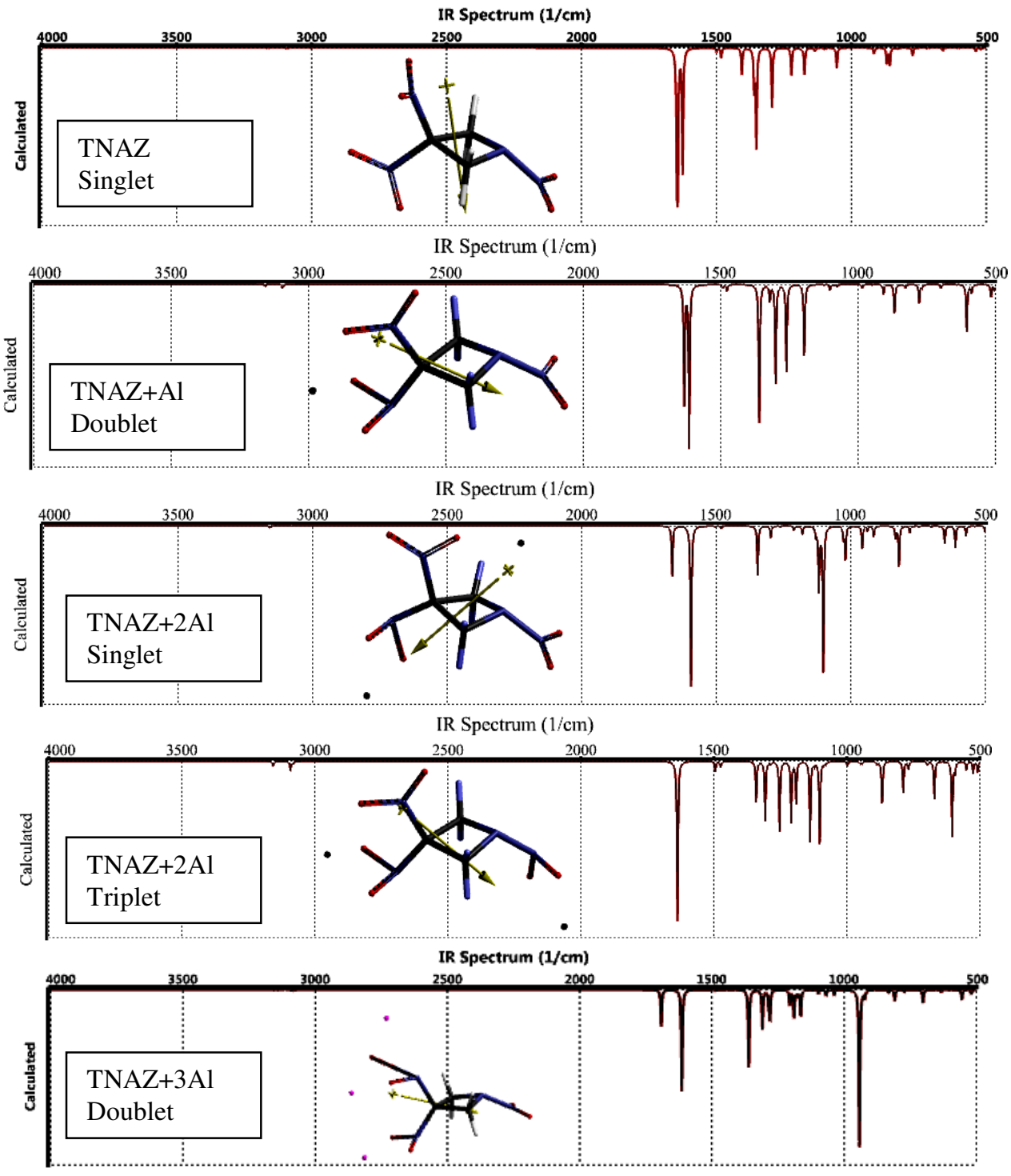

IR Spectrum (1/cm)

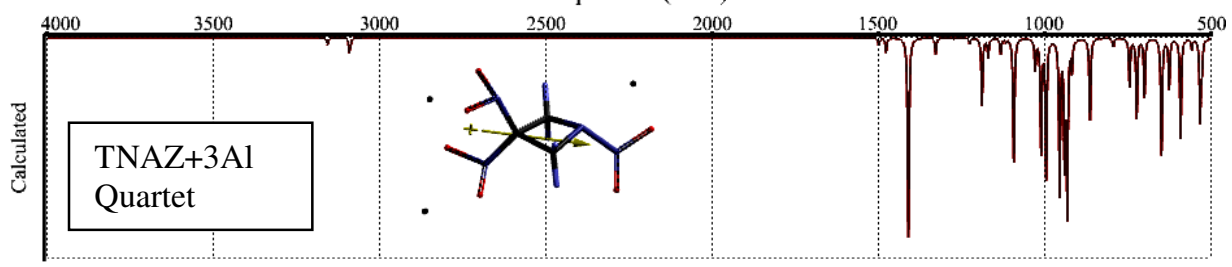

Figure 6. IR spectra of the composites (UB3LYP/6-311++G(d,p)). 
level of UB3LYP/6-311++G(d,p). At first sight it is evident that the IR spectra are highly structure, thus multiplicity dependent.

IR spectrums of TNAZ (singlet) and TNAZ+Al (doublet) are quite similar. The sharp peaks at $1632 \mathrm{~cm}^{-1}$ and $1614 \mathrm{~cm}^{-1}$ are asymmetric $\mathrm{N}-\mathrm{O}$ stretchings of $\mathrm{NO}_{2}$ groups (the geminal and nitramine nitro groups, respectively). In the case of TNAZ+2Al (singlet), the peaks at $1663 \mathrm{~cm}^{-1}$ and $1593 \mathrm{~cm}^{-1}$ are N-O stretchings of nitramine and geminal $\mathrm{NO}_{2}$ groups, respectively. TNAZ+2Al (triplet) spectrum is very different from the corresponding singlet composite. The peaks at $1636 \mathrm{~cm}^{-1}$ is asymmetric N-O stretching of the geminal nitro groups. TNAZ+3Al doublet has sharp peaks at $1692 \mathrm{~cm}^{-1}$ and 1614 $\mathrm{cm}^{-1}$ which stand for $\mathrm{N}-\mathrm{O}$ stretchings of the geminal and nitramine nitro groups. In the case of TNAZ+3Al quartet the peak at $1410 \mathrm{~cm}^{-1}$ is the asymmetric N-O stretching of nitramine nitro group.

Figure 7 displays electrostatic charges (at the level of UB3LYP/6-311++G(d,p)) on the atoms based on electrostatic potential (ESP). The ESP charges are obtained by the program based on a numerical method that generates charges that reproduce the electrostatic potential field from the entire wavefunction [35]. In all the cases $\mathrm{Al}$ atom(s) acquire some positive partial charges, except in the quartet case of TNAZ+3Al system in which one of the aluminum atoms gets some partial negative charge.

The positive partial charges (less than unity) on aluminum atoms indicate that some electron population has been transferred to TNAZ molecule in such composites. Those gained electron population should have been populated on the atoms and in the bonds. Thus, the bond strengths of TNAZ molecule in the composites should vary according to the number of $\mathrm{Al}$ atoms and the multiplicity of the composite systems. That is why the IR spectra are highly different from each other. 

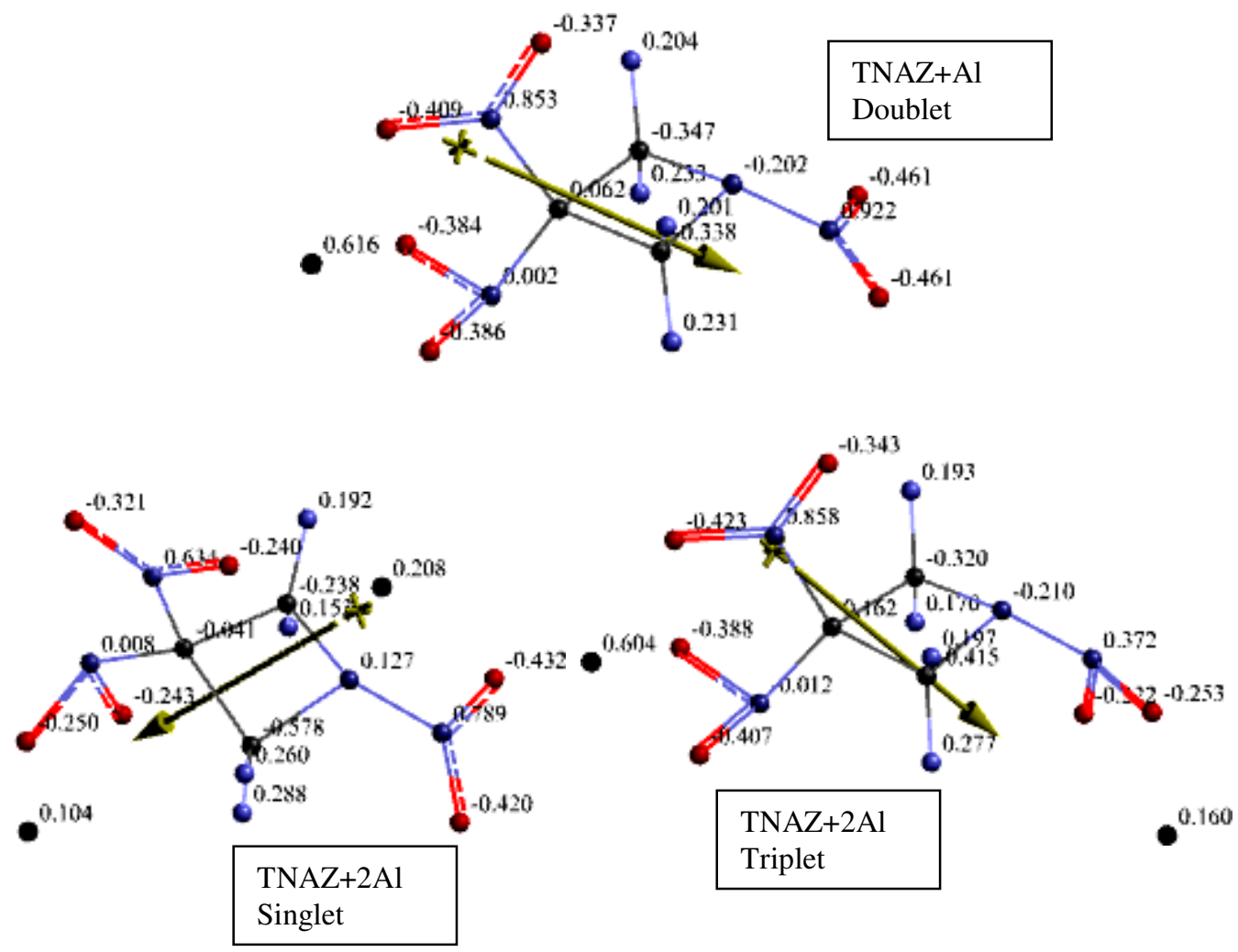

$\mathrm{e}^{0.024}$
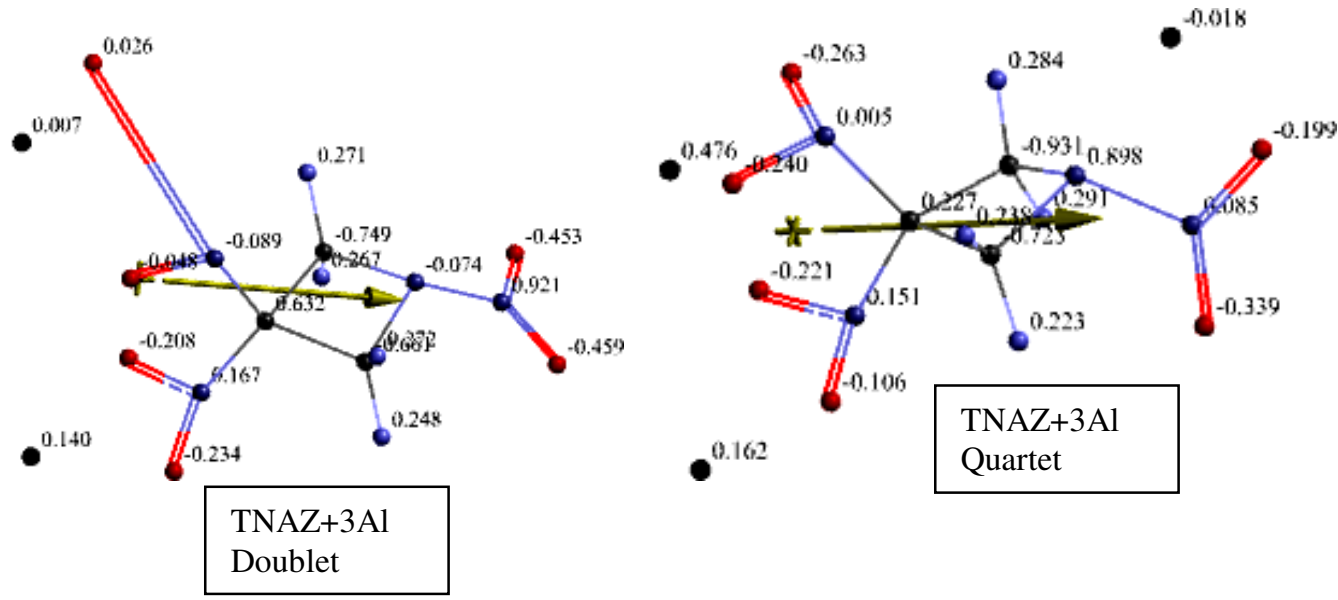

Figure 7. Electrostatic charges (ESP) on the atoms of the composites (UB3LYP/6$311++G(d, p))$. 
Figure 8 shows the ESP charges calculated at the level of UB3LYP/cc-PVDZ. In this case aluminum atoms acquire positive partial charge except TNAZ+3Al doublet and quartet cases in which one of the $\mathrm{Al}$ atoms has tiny amount of partial negative charge. Note that in both of the results of calculation methods for TNAZ+3Al quartet case the same $\mathrm{Al}$ atom get the negative charge.
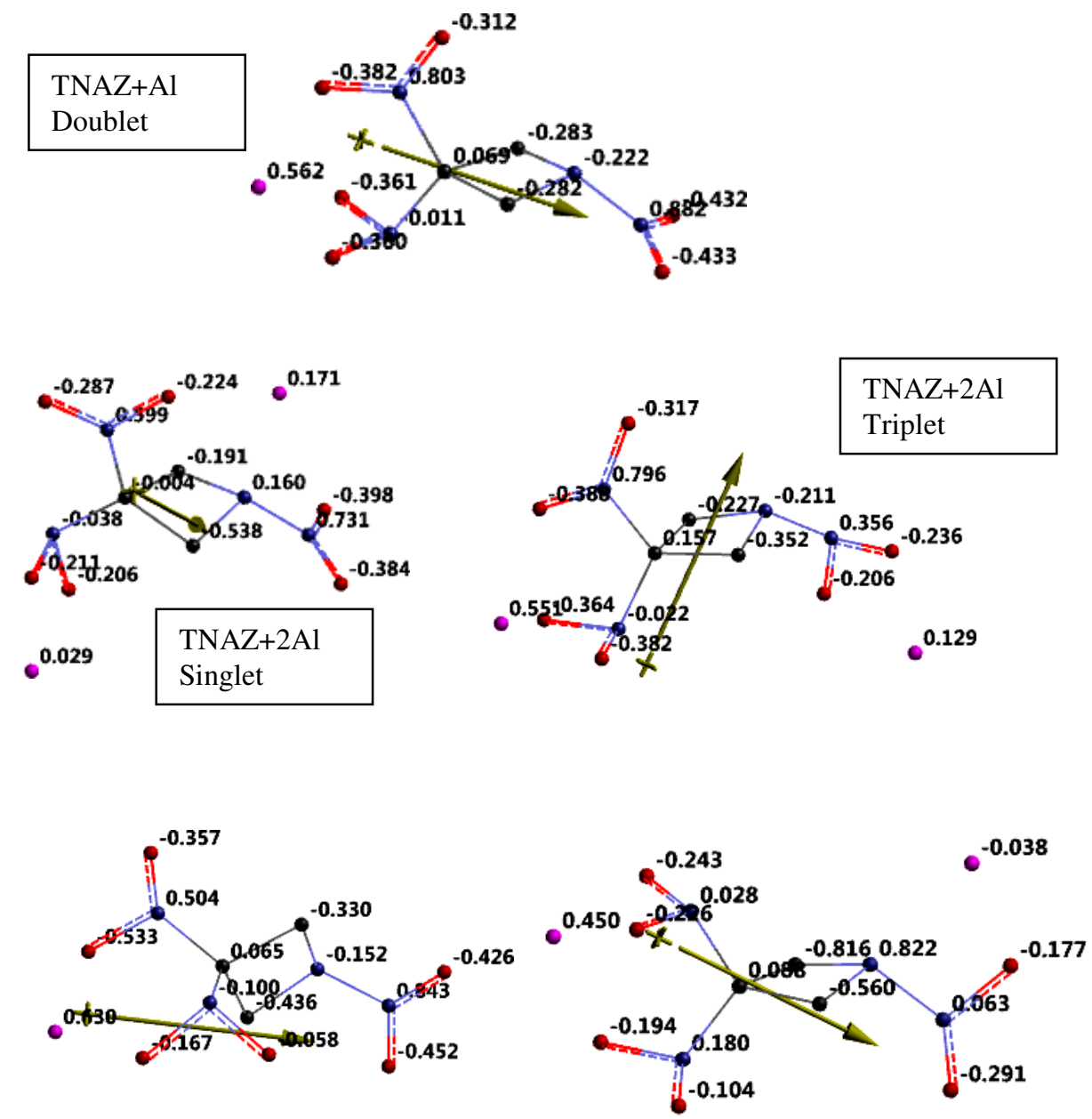

$0^{0.211}$
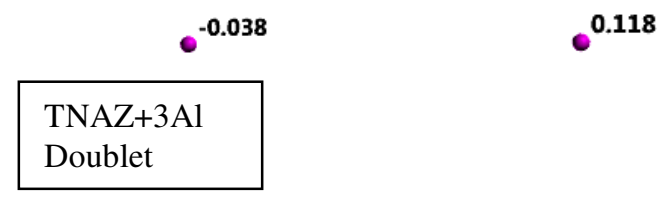

TNAZ+3Al

Quartet

Figure 8. Electrostatic charges (ESP) on the atoms of the composites (UB3LYP/ccPVDZ). 
Figure 9 shows the spin densities of the aluminized TNAZ systems possessing openshell structures. The blue and red colored regions stand for low and relatively rich unpaired spin populations, respectively. It is to be noted that UB3LYP/cc-PVDZ level of calculations result similar spin density plots as the other level of calculation employed (see Figure 9).
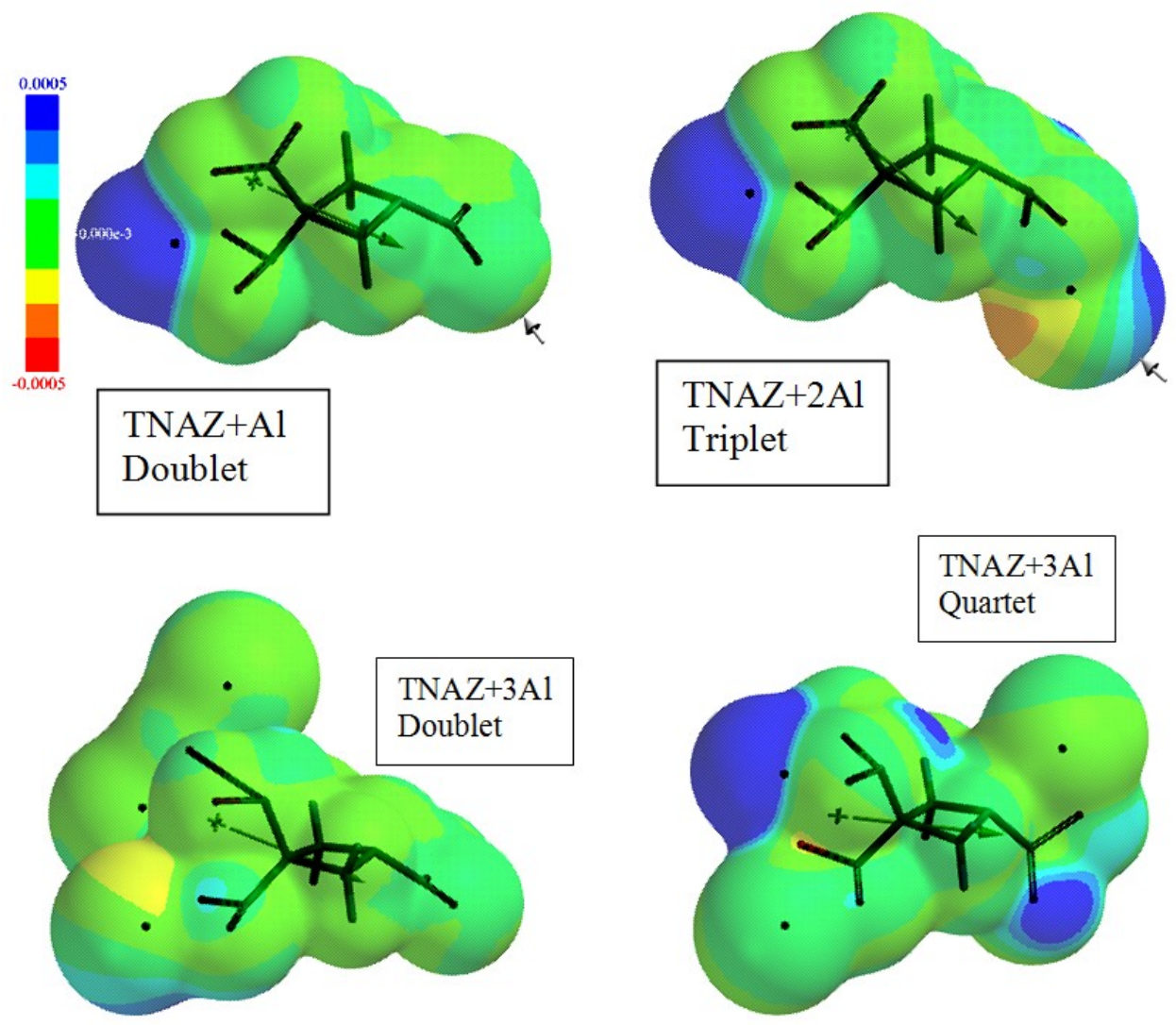

Figure 9. Spin densities on the composites having open-shell systems (UB3LYP/6$311++G(d, p))$.

Table 2 shows the total electronic energy (E), zero point vibrational energy (ZPE) and the corrected total electronic energy $\left(\mathrm{E}_{\mathrm{c}}\right)$ values for the composite systems of present concern. In each row the first and second entries stand for energies obtained at UB3LYP/6-311++G(d,p) and UB3LYP/cc-PVDZ level of calculations, respectively. When $E_{c}$ values are compared for the isomeric structures, the system having higher spin 
state is more stable than the other for $n: 2$. It is also true for $n: 3$ at the UB3LYP/6$311++\mathrm{G}(\mathrm{d}, \mathrm{p})$ level, however, at the UB3LYP/cc-PVDZ level the quartet state is more stable than the doublet. For energies of isomeric structures B3LYP functional bias in favor of one type of spin states of isomeric structures [37-40]. In the case of some aluminized explosives lower spin state is favored (UB3LYP/6-311++G(d,p)) [41-43].

Table 2. Various energies of the composites.

\begin{tabular}{|c|c|c|c|}
\hline Structure & $\mathbf{E}$ & ZPE & $\mathbf{E}_{\mathbf{c}}$ \\
\hline $\mathrm{TNAZ}+\mathrm{Al}$ & -2702813.27 & 277.18 & -2702536.09 \\
\hline Doublet & -2702343.34 & 277.83 & -2702065.51 \\
\hline $\mathrm{TNAZ}+2 \mathrm{Al}$ & -3339321.12 & 276.03 & -3339045.09 \\
\hline Singlet & -3338845.66 & 276.42 & -3338569.24 \\
\hline $\mathrm{TNAZ}+2 \mathrm{Al}$ & -3339401.07 & 275.15 & -3339125.92 \\
\hline Triplet & -3338926.52 & 275.75 & -3338650.77 \\
\hline $\mathrm{TNAZ}+3 \mathrm{Al}$ & -3976193.00 & 272.28 & -3975920.72 \\
\hline Doublet & -3975550.09 & 279.66 & -3975270.43 \\
\hline $\mathrm{TNAZ}+3 \mathrm{Al}$ & -3976040.19 & 272.98 & -3975767.21 \\
\hline Quartet & -3975555.5 & 273.12 & -3975282.38 \\
\hline
\end{tabular}

Figure 10 displays some of the molecular orbital energy levels of the aluminized composites. Note that the open shell systems (doublet, triplet and quartet) have $\alpha$ - and $\beta$ type orbitals in unrestricted treatment. In Figure 10 those are indicated as a- and b-types. As seen in the figure the $\beta$-HOMO levels are noticeably lower than the $\alpha$-HOMOs (except the doublet of TNAZ+3Al case).

The electronic stability is an implicit function of electron distribution in the molecule. Hence, the stabilities are affected by the multiplicities in the case of isomeric composites. Note that the composite having more deeply lying occupied molecular orbitals, being the other factors same, should have higher stability as compared to others. 


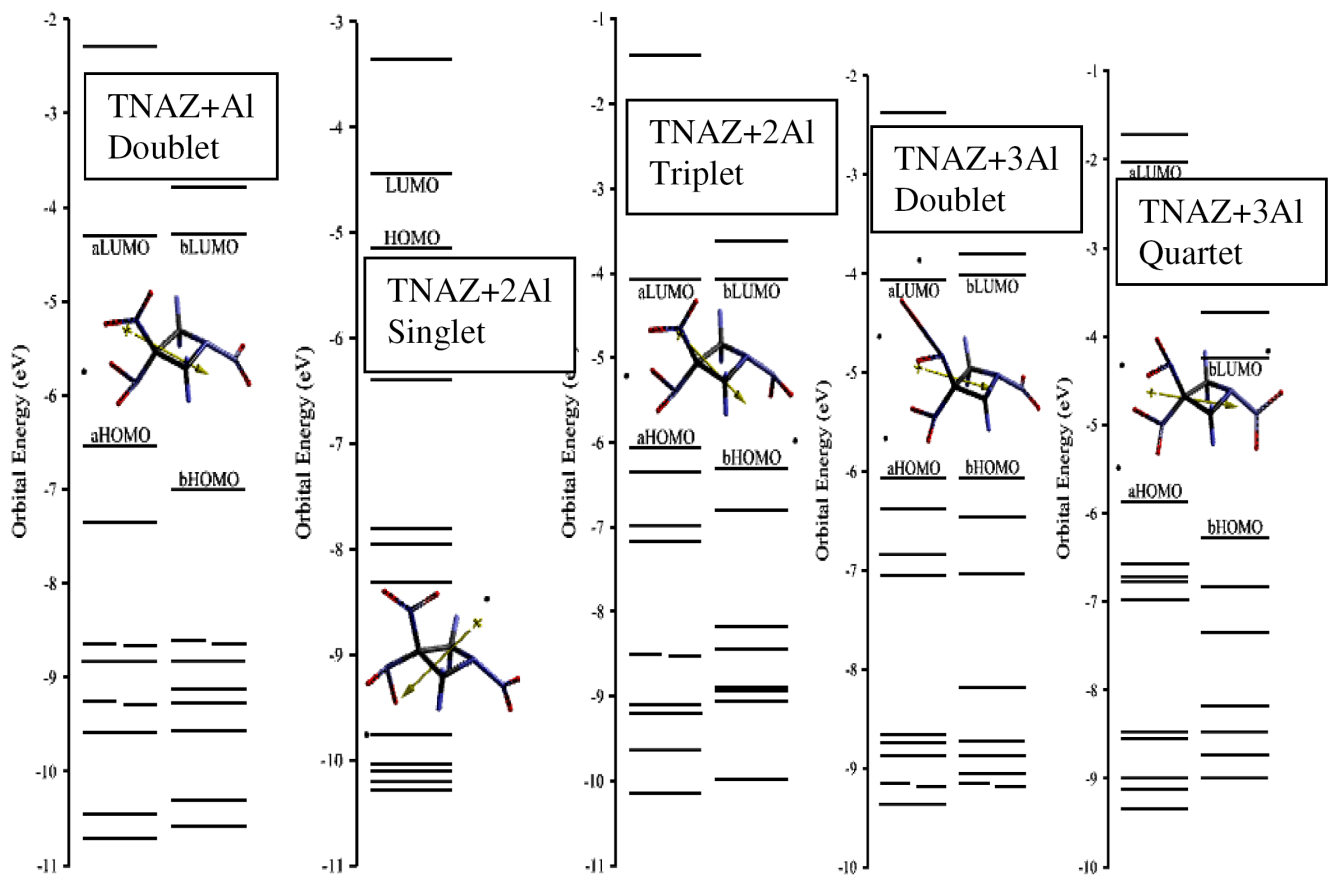

Figure 10. Some of the molecular orbital energy levels of the composites (UB3LYP/6$311++\mathrm{G}(\mathrm{d}, \mathrm{p}))$.

Table 3 displays that the HOMO levels follow the order of $\mathrm{Al}(\mathrm{d})<3 \mathrm{Al}(\mathrm{d})<2 \mathrm{Al}(\mathrm{t})<3 \mathrm{Al}(\mathrm{q})<2 \mathrm{Al}(\mathrm{s})$ at the UB3LYP/6-311++G(d,p) level and $\mathrm{Al}(\mathrm{d})<2 \mathrm{Al}(\mathrm{t})<3 \mathrm{Al}(\mathrm{d})<3 \mathrm{Al}(\mathrm{q})<2 \mathrm{Al}(\mathrm{s})$ at the UB3LYP/cc-PVDZ level. As for the LUMO energies, $2 \mathrm{Al}(\mathrm{s})<\mathrm{Al}(\mathrm{d})<2 \mathrm{Al}(\mathrm{t})<3 \mathrm{Al}(\mathrm{d})<3 \mathrm{Al}(\mathrm{q})$ at the UB3LYP/6-311++G(d,p) level and $2 \mathrm{Al}(\mathrm{s})<\mathrm{Al}(\mathrm{d})<2 \mathrm{Al}(\mathrm{t})<3 \mathrm{Al}(\mathrm{d})<3 \mathrm{Al}(\mathrm{q})$ at the UB3LYP/cc-PVDZ level. As the consequences of those HOMO and LUMO orders the LUMO-HOMO energy differences $(\Delta \varepsilon)$ follows the order of $2 \mathrm{Al}(\mathrm{s})<2 \mathrm{Al}(\mathrm{t})<3 \mathrm{Al}(\mathrm{d})<\mathrm{Al}(\mathrm{d})<3 \mathrm{Al}(\mathrm{q})$ at the UB3LYP/6$311++\mathrm{G}(\mathrm{d}, \mathrm{p})$ level, whereas the order becomes $2 \mathrm{Al}(\mathrm{s})<3 \mathrm{Al}(\mathrm{d})<2 \mathrm{Al}(\mathrm{t})<\mathrm{Al}(\mathrm{d})<3 \mathrm{Al}(\mathrm{q})$ at the UB3LYP/cc-PVDZ level. The interfrontier molecular orbital energy difference, $\Delta \varepsilon$, is the smallest for $2 \mathrm{Al}(\mathrm{s})$ at each level of calculations but the largest for $3 \mathrm{Al}(\mathrm{q})$ cases. Therefore, TNAZ $+2 \mathrm{Al}$ composite could have some excitation at the IR region. 
Table 3. HOMO and LUMO energies and $\Delta \varepsilon$ values of the composites.

\begin{tabular}{lccc}
\hline Structure & HOMO & LUMO & $\boldsymbol{\Delta \varepsilon}$ \\
\hline TNAZ+ Al & -630.91 & -415.06 & 215.85 \\
Doublet & -605.33 & -377.42 & 227.91 \\
TNAZ+ 2Al & -497.04 & -428.19 & 68.85 \\
Singlet & -471.33 & -399.19 & 72.14 \\
TNAZ+ 2Al & -585.56 & -393.72 & 191.84 \\
Triplet & -566.33 & -360.72 & 205.61 \\
TNAZ+ 3Al & -585.67 & -391.65 & 194.02 \\
Doublet & -554.18 & -356.15 & 198.03 \\
TNAZ+ 3Al & -565.87 & -195.06 & 370.81 \\
Quartet & -546.1 & -184.23 & 361.87 \\
\hline
\end{tabular}

Energies in $\mathrm{kJ} / \mathrm{mol}$. The first and second entries in each row are energies of UB3LYP/6-311++G(d,p) and UB3LYP/cc-PVDZ levels, respectively.

From Figure 11 which displays the time dependent UV-VIS spectrums ((UB3LYP/6$311++\mathrm{G}(\mathrm{d}, \mathrm{p}))$ of the aluminum composites of TNAZ, it is observed that all the composites considered except, TNAZ+Al case, exhibit bathochromic shift beyond the visible towards IR region of the spectrum.
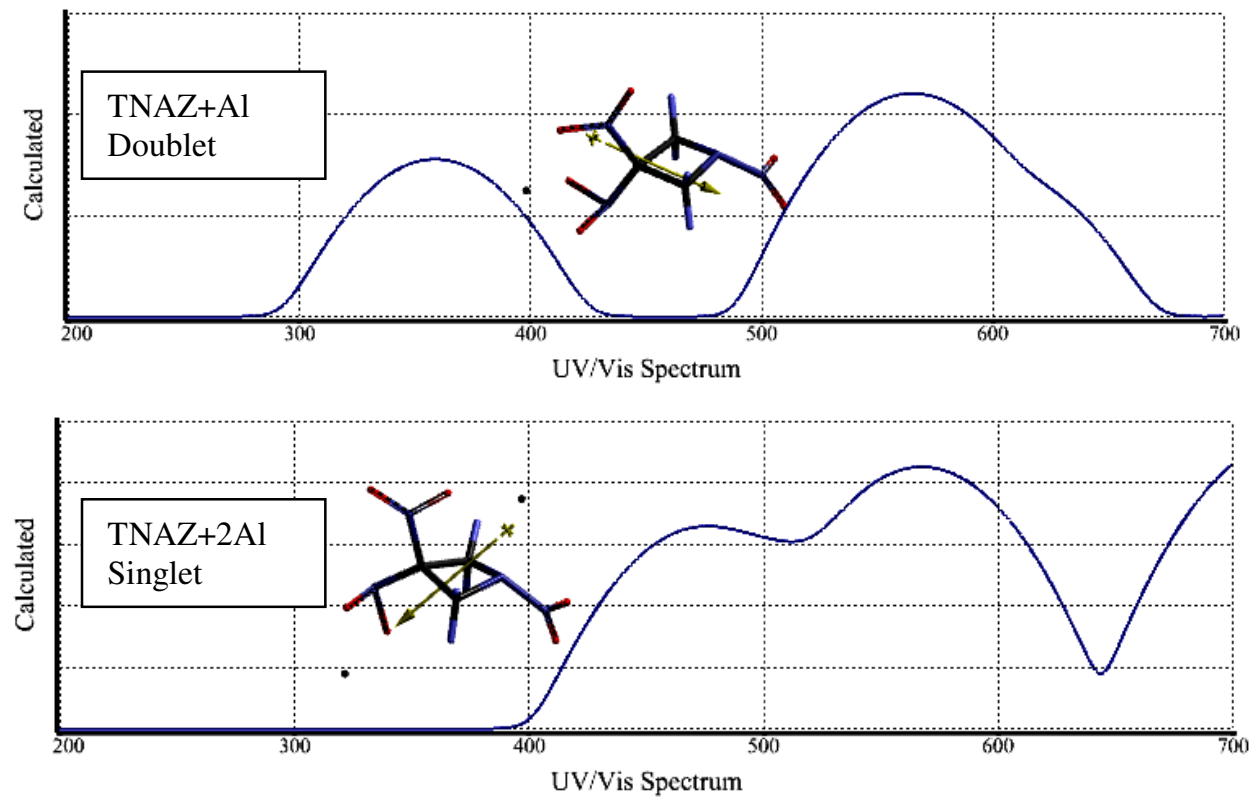

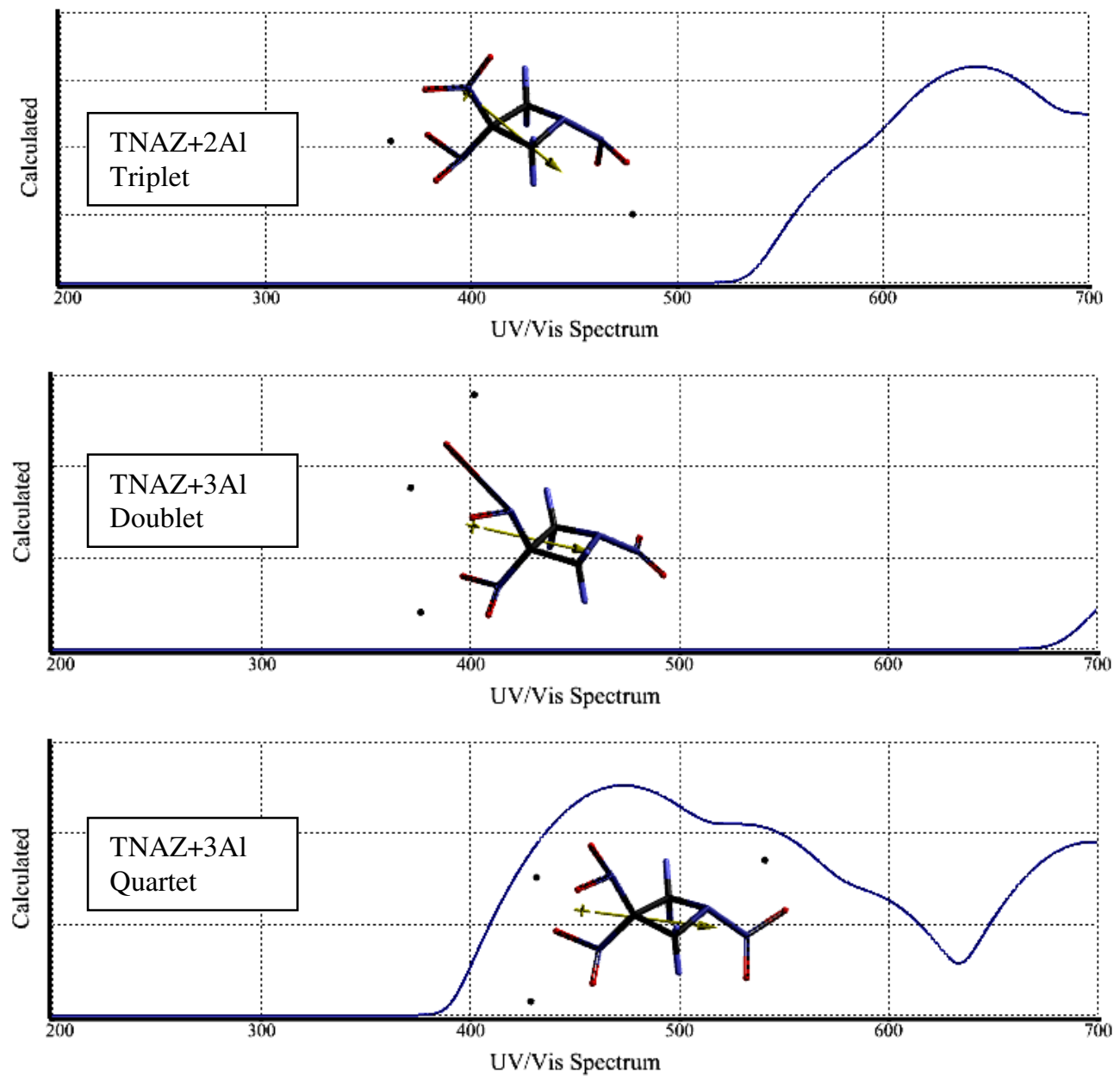

Figure 11. UV-VIS spectra of the composites (UB3LYP/6-311++G(d,p)).

\section{Conclusions}

The present DFT treatment of some aluminized TNAZ composites at the molecular level reveals that various properties of them are highly dependent on the number of aluminum atoms, thus the multiplicities of the composites considered. It should be kept in mind that in the bulk the local orientation of $\mathrm{Al}$ atoms around TNAZ molecule is dictated not only by statistical factors but intra and inter molecular forces as well. Consequently, the composition and way of preparation of the composite may cause ample possibilities for various properties of them including the ballistic ones. 


\section{References}

[1] P. F. Pagoria, G. S. Lee, R. A. Mitchell and R. D Schmidt, A review of energetic materials synthesis, Thermochim. Acta 384 (2002), 187-204.

https://doi.org/10.1016/S0040-6031(01)00805-X

[2] H. S. Jadhav, M. B. Talawar, D. D. Dhavale, S. N. Asthana and V. V. Krishnamurthy, Alternate method to synthesis of 1,3,3-trinitroazetedine (TNAZ): Next generation melt castable high energy material, Indian J. Chemical Technology 13 (2006), 41-46.

[3] T. G. Archibald, R. Gilardi, K. Baum and C. J. George, Synthesis and x-ray crystal structure of 1,3,3-trinitroazetidine, J. Org. Chem. 55 (1990), 2920-2924.

https://doi.org/10.1021/jo00296a066

[4] R. L. McKenney, Jr., T. G. Floyd, W. E. Stevens, T. G. Archibald, A. P. Marchand, G. V. M. Sharma and S. G. Bott, Synthesis and thermal properties of 1,3-dinitro-3-(1', 3'dinitroazetidin-3'-yl) azetidine (tndaz) and its admixtures with 1,3,3-trinitroazetidine (TNAZ), J. Energ. Mater. 16 (1998), 199-235. https://doi.org/10.1080/07370659808217513

[5] A. M. Hiskey, M. C. Johnson and E. D. Chavez, Preparation of 1-substituted-3, 3dinitroazetidines, J. Energ. Mater. 17 (1999), 233-252.

https://doi.org/10.1080/07370659908216106

[6] J. Zhang, R. Hu, C. Zhu, G. Feng and Q. Long, Thermal behavior of 1,3,3trinitroazetidine, Thermochim. Acta 298 (1997), 31-35.

https://doi.org/10.1016/S0040-6031(97)00056-7

[7] S. Zeman, The thermoanalytical study of some amino derivatives of 1,3,5-trinitrobenzene, Thermochim. Acta 216 (1993), 157-168. https://doi.org/10.1016/0040-6031(93)80389-R

[8] M. H. Keshavarz, Approximate prediction of melting point of nitramines, nitrate esters, nitrate salts and nitroaliphatics energetic compounds, J. Hazard. Mater. A138 (2006), 448-451. https://doi.org/10.1016/j.jhazmat.2006.05.097

[9] Z. Jalovy, S. Zeman, M. Suceska, P. Vavra, K. Dudek and J. M. Rajic, 1,3,3Trinitroazetidine (TNAZ). Part I. Syntheses and properties, J. Energ. Mater. 19 (2001), 219-239. https://doi.org/10.1080/07370650108216127

[10] D. S. Watt and M. D. Cliff, Evaluation of 1,3,3-trinitroazetidine (TNAZ) - A high performance melt-castable explosive, Technical Report DSTO-TR-1000, Defence Science \& Technology Organization (DSTO), Aeronautical and Maritime Research Laboratory, Melbourne, Australia, 2000. 
[11] A. K. Sikder and N. Sikder, A review of advanced high performance, insensitive and thermally stable energetic materials emerging for military and space applications, $J$. Hazard. Mater. A112 (2004), 1-15. https://doi.org/10.1016/j.jhazmat.2004.04.003

[12] S. Iyer, E. Y. Sarah, M. Yoyee, R. Perz, J. Alster and D. Stoc, TNAZ based composition C-4 development, 11th Annual Working Group, Institute on Synthesis of High Density Materials (Proc.), Kiamesha Lakes, 1992.

[13] M. Oftadeh, M. Hamadanian, M. Radhoosh and M. H. Keshavarz, DFT molecular orbital calculations of initial step in decomposition pathways of TNAZ and some of its derivatives with $-\mathrm{F},-\mathrm{CN}$ and $-\mathrm{OCH} 3$ groups, Computational and Theoretical Chemistry 964 (2011), 262-268. https://doi.org/10.1016/j.comptc.2011.01.007

[14] J. O. Doali, R. A. Fifer, D. I. Kruzezynski and B. J. Nelson, The mobile combustion diagnostic fixture and its application to the study of propellant combustion Part-I. Investigation of the low pressure combustion of LOVA XM-39 Propellant, Technical Report No: BRLMR-3787/5, US Ballistic Research Laboratory, Maryland, 1989.

[15] J. P. Agrawal, Recent trends in high-energy materials, Prog. Energ. Combust. Sci. 24/1 (1998), 1-30. https://doi.org/10.1016/S0360-1285(97)00015-4

[16] M. D. Coburn and M. A. Hiskey, T. G. Archibald, Scale-up and waste-minimization of the Los Alamos process for 1,3,3-trinitroazetidine (TNAZ), Waste Management 17 (1997), 143-146. https://doi.org/10.1016/S0956-053X(97)10013-7

[17] L. Jizhen, F. Xuezhong, F. Xiping, Z. Fengqi and H. Rongzu, Compatibility study of 1,3,3-trinitroazetidine with some energetic components and inert materials, Journal of Thermal Analysis and Calorimetry 85(3) (2006), 779-784.

https://doi.org/10.1007/s10973-005-7370-8

[18] L. Türker and S. Varis, Desensitization of TNAZ via molecular structure modification and explosive properties - A DFT study, Acta Chim. Slov. 59 (2012), 749-759.

[19] J. Wu, Y. Huang, L. Yang, D. Geng, F. Wang, H. Wang and L. Chen, Reactive molecular dynamics simulations of the thermal decomposition mechanism of 1,3,3-trinitroazetidine, Chem. Phys. Chem. 19(20) (2018), 2683-2695. https://doi.org/10.1002/cphc.201800550

[20] P. P. Vadhe, R. B. Pawar, R. K. Sinha, S. N. Asthana and A. Subhananda Rao, Cast aluminized explosives (review), Combustion Explosion and Shock Waves 44(4) (2008), 461-477. https://doi.org/10.1007/s10573-008-0073-2

[21] A. E. Wildegger-Gaissmaier, Aspects of thermobaric weaponry, Military Technology 28(6) (2004), 125-126. 
[22] N. H. Yen and L. Y. Wang, Reactive metals in explosives, Propellants Explos. Pyrotech. 37(2) (2012), 143-155. https://doi.org/10.1002/prep.200900050

[23] M. A. Cook, A. S. Filler, R. T. Keyes, W. S. Partridge and W. Ursenbach, Aluminized explosives, J. Phys. Chem. 61(2) (1957), 189-196. https://doi.org/10.1021/j150548a013

[24] L. Türker, Thermobaric and enhanced blast explosives (TBX and EBX), Defence Technology 12(6) (2016), 423-445. https://doi.org/10.1016/j.dt.2016.09.002

[25] J. J. P. Stewart, Optimization of parameters for semiempirical methods I. Method, J. Comput. Chem. 10 (1989), 209-220. https://doi.org/10.1002/jcc.540100208

[26] J. J. P. Stewart, Optimization of parameters for semi empirical methods II. Application, J. Comput. Chem. 10 (1989), 221-264. https://doi.org/10.1002/jcc.540100209

[27] A. R. Leach, Molecular Modeling, Essex: Longman, 1997.

[28] P. Fletcher, Practical Methods of Optimization, New York: Wiley, 1990.

[29] W. Kohn and L. Sham, Self-consistent equations including exchange and correlation Effects, J. Phys. Rev. 140 (1965), 1133-1138.

https://doi.org/10.1103/PhysRev.140.A1133

[30] R. G. Parr and W. Yang, Density Functional Theory of Atoms and Molecules, London: Oxford University Press, 1989.

[31] C. J. Cramer, Essentials of Computational Chemistry, Chichester, West Sussex: Wiley, 2004.

[32] A. D. Becke, Density-functional exchange-energy approximation with correct asymptotic behavior, Phys. Rev. A 38 (1988), 3098-3100.

https://doi.org/10.1103/PhysRevA.38.3098

[33] S. H. Vosko, L. Vilk and M. Nusair, Accurate spin-dependent electron liquid correlation energies for local spin density calculations: a critical analysis, Can. J. Phys. 58 (1980), 1200-1211. https://doi.org/10.1139/p80-159

[34] C. Lee, W. Yang and R.G. Parr, Development of the Colle-Salvetti correlation-energy formula into a functional of the electron density, Phys. Rev. B 37 (1988), 785-789.

https://doi.org/10.1103/PhysRevB.37.785

[35] SPARTAN 06, Wavefunction Inc., Irvine CA, USA, 2006.

[36] L. V. Vilkov, V. S. Mastryukov and N. I. Sadova, Determination of the Geometrical Structure of Free Molecules, Moscow: Mir Pub, 1983. 
[37] O. Salomon, M. Reiher and B. A. Hess, Assertion and validation of the performance of the B3LYP* functional for the first transition metal row and the G2 test set, J. Chemical Physics 117(10) (2002), 4729-4737. https://doi.org/10.1063/1.1493179

[38] D. M. A. Smith, M. Dupuis and T. P. Straatsma, Multiplet splittings and other properties from density functional theory: an assessment in iron-porphyrin systems, J. Mol. Phys. 103(2-3), (2005), 273-278. https://doi.org/10.1080/00268970512331317309

[39] M. Radoń, Toward accurate spin-state energetics of transition metal complexes, Advances in Inorganic Chemistry 73 (2019), 221-264.

https://doi.org/10.1016/bs.adioch.2018.10.001

[40] D. Coskun, S. V. Jerome and R. A. Friesner, Evaluation of the performance of the B3LYP, PBE0, and M06 DFT functionals, and DBLOC-corrected versions, in the calculation of redox potentials and spin splittings for transition metal containing systems, J. Chem. Theory Comput. 12(3) (2016), 1121-1128.

https://doi.org/10.1021/acs.jctc.5b00782

[41] L. Türker, Effect of aluminum on FOX-7 structure, Chinese J. Explosives Propellants 42(3) (2019), 213-231.

[42] L. Türker, Interaction of 1,1-diamino-2,2-dinitroethylene and gallium - DFT treatment, Earthline J. Chem. Sci. 2(2) (2019), 271-291. https://doi.org/10.34198/ejcs.2219.271291

[43] L. Türker, RDX-aluminum interaction-A DFT study, Chinese J. Explosives Propellants 39(4) (2016), 12-18. 